\title{
Häufig verwendete Formelzeichen
}

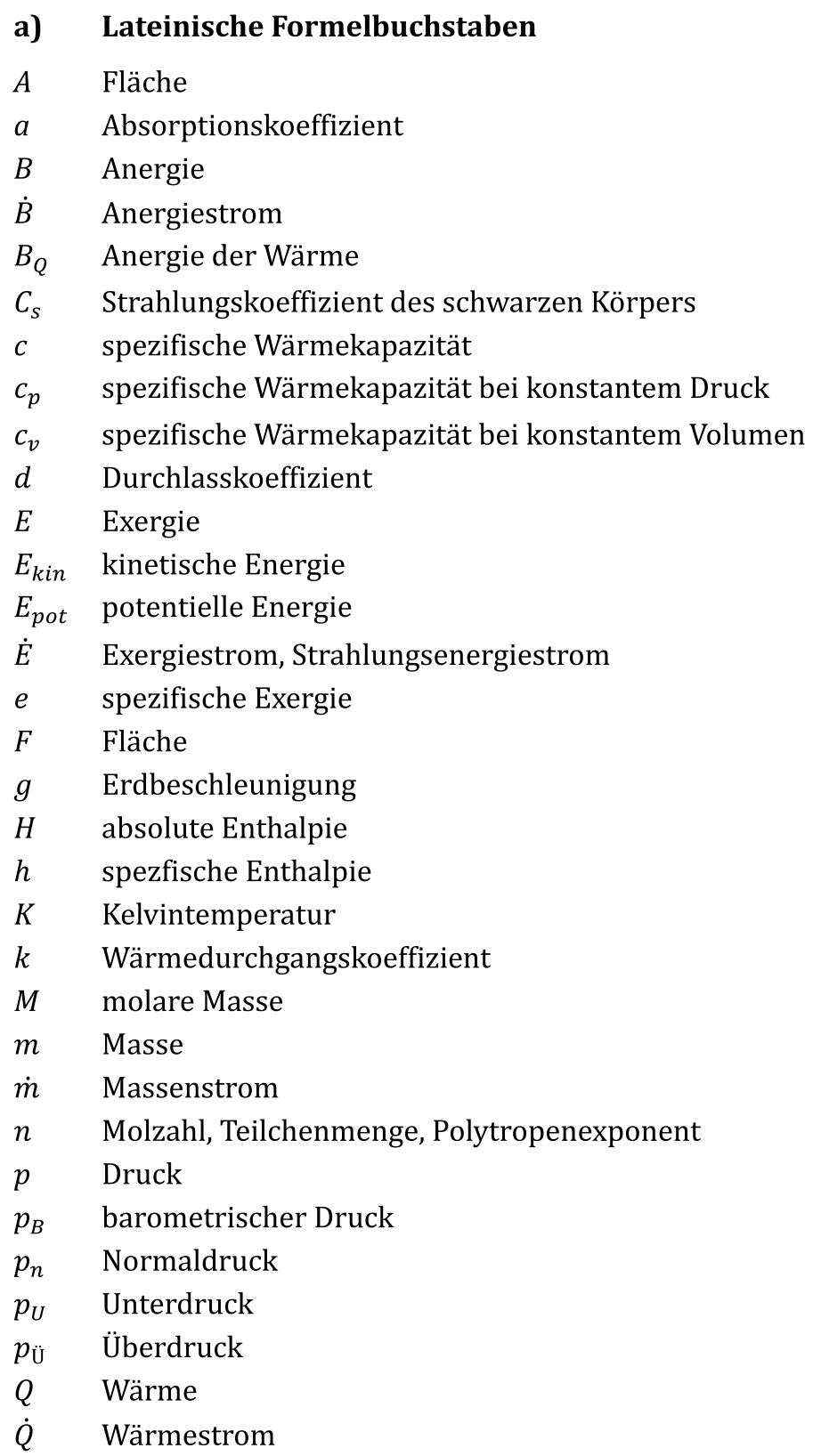


$q \quad$ spezifische Wärme

$\dot{q} \quad$ spezifischer Wärmestrom

$R \quad$ spezielle Gaskonstante, elektrischer Widerstand

$R_{T} \quad$ thermischer Widerstand

$\bar{R} \quad$ universelle Gaskonstante

$r \quad$ Reflexionskoeffizient

$S \quad$ Entropie

$\dot{S} \quad$ Entropiestrom

$S_{i r r}$ irreversible Entropie

$s \quad$ spezifische Entropie

$T \quad$ Kelvintemperatur

$T_{n} \quad$ Normaltemperatur

$t \quad$ Celsiustemperatur

$U$ absolute innere Energie

$u \quad$ spezifische innere Energie

$v \quad$ Volumen

$\dot{V} \quad$ Volumenstrom

$v \quad$ spezifisches Volumen

$\bar{v} \quad$ molares Volumen

$\bar{v}_{n} \quad$ Norm-Molvolumen

$W$ absolute Arbeit

$W_{t} \quad$ absolute technische Arbeit

$W_{D, n t}$ absolute Arbeit der Druckkräfte (Oberflächenkräfte)

$W_{R} \quad$ absolute Arbeit der Reibungskräfte

$\dot{W} \quad$ Arbeitsstrom

$w \quad$ spezifische Arbeit

$w_{t} \quad$ spezifische technische Arbeit

$w_{D, n t}$ spezifische Arbeit der Druckkräfte (Oberflächenkräfte)

$w_{R} \quad$ spezifische Arbeit der Reibungskräfte

$\dot{w} \quad$ spezifischer Arbeitsstrom

$x \quad$ Koordinate

$y \quad$ Koordinate

Z Realgasfaktor

Z Koordinate

b) Griechische Formelbuchstaben

$\alpha \quad$ Wärmeübergangskoeffizient

$\delta \quad$ Schichtdicke

$\varepsilon \quad$ Emissionskoeffizient 
$\eta_{t h} \quad$ thermischer Wirkungsgrad einer Wärmekraftmaschine

$\eta_{C} \quad$ CARNOT-Faktor

$\lambda$ Wärmeleitkoeffizient

$\kappa \quad$ Isentropenexponent

$\rho \quad$ Dichte 
